\title{
ASSESSMENT AND OPTIMIZATION OF HUMAN FACTORS
}

\author{
L.A. LIEBE$^{1} \&$ R.J. LIEBE 2 \\ ${ }^{1}$ Per Opti e.K., Monheim am Rhein, Germany. \\ ${ }^{2}$ Turbo-improve-consult, Monheim am Rhein, Germany.
}

\begin{abstract}
Accelerating global growth and frequent man-made crises generate uncertainties and demand new alternatives and viable solutions in technology, energy, and health as well as political, ecological, and media organizations. This paper focuses on the key role of human communication and the increasing significance of "human factors' (HF). In technology, currently 70 to $90 \%$ of all deficiencies originate from the complex HF-area, which includes human errors as well. In spite of human complexity, it is useful to study nature and compare it with our communication and behavior. Starting from control engineering and biocybernetics, a simple building block is discussed: the control circuit with negative feedback and stability. Two examples are then presented from biology and mechanics to illustrate communication, cooperation, self-regulation and stabilizing mechanisms: (i) The mutualism between a tree and animals with fast adaptation to new symbioses and (ii) The elastoplastic, self-controlled buckling with 'snap-through' and stabilizing mechanisms. Observing human behaviour and nature lead to an integral mental approach with the Limbionik ${ }^{\circledR}$ Method (LM), which focuses on inter- and intrapersonal communication. The HF is assessed, utilizing what is called the UB or 'Urbewusstsein'. Next the objectives, assumptions, features and the basic LM methodology are discussed in detail. First experience with individuals and small groups is reported, covering success, performance, work and health. Generally speaking, the LM makes individuals and organizations fit for the accelerating pace of today's life. Three examples illustrate a successful LM application: (i) The treatment of clients, suffering from a burnout syndrome. Self-realization of their UB with personal filters leads them to choose a stable, lasting recovery path. (ii) A Six-Sigma project support in engineering and fabrication of large steam turbines. Including the HF into Six Sigma allowed to identify the majority of human-related root causes (80\% of total) and define remedies. (iii) An engineering/fabrication improvement project for large turbogenerators, involving the varnishing process of stator core sheets. Corrections included the introduction of robust machine and human processes. After summarizing the salient characteristics of the LM philosophy, future activities on both HF and LM are outlined. Keywords: organizations, change management, communication, self-motivation, performance, responsibility, human factors, human error, success, process capability, robustness, sustainability, individuals, perception, stability, negative feedback, burnout syndrome, learning from nature.
\end{abstract}

\section{INTRODUCTION}

In our dynamic, increasingly tight world, the individual does not overlook anymore the dense, global inter-relations with resulting fast and drastic changes. The current world population of seven billion people will reach circa ten billion by 2050, two-thirds of which will live in big cities. Accelerating economic growth, global collapses, and instabilities are typical for today. We consume faster than the environment produces. Worldwide exploitation of resources and frequent man-made disasters raise worries and trigger the need for creative, alternative routes for technology, energy, and health care - economy and finance - political, ecological, and media organizations. We need to work with nature and not against it [1]. Dense human international cross-linking underlines the importance of communication [2]. In addition, the human factors [3, 4] are going to play an increasing role in future.

This paper focuses on an integral, new approach to improve the constitution of individuals and the quality of decision-making in groups and organizations. Starting out with some thoughts about communication and human factors including human errors $[4,5]$, the control loop with feedback is discussed as the basic element. Next it is shown how observation of nature gives insight into basic principles of general design, construction of robust, intermeshed control systems and how to cope 
with complex organisms [6-8]. Examples are given for systems in mechanics as well as in biology and zoology [9-11]. All of them demonstrate the system behavior far off its equilibrium, mechanisms to establish new, stable and optimum configurations - as well as general adaptability, including cooperation and symbiosis in evolution [8, 12-18].

Inspirations from observing nature as well as human behavior lead to the development of the Limbionik ${ }^{\circledR}$ Method (LM) [19]. Origin, main features, and the purpose of this method are described in detail. Underlying assumptions and models are discussed as well. In this context particular emphasis is given to the "Unbewusstsein" (UB), including the resulting intra- and interpersonal interactions on several levels. Next a practical application is described: the successful assessment and cure of burnout syndromes in individuals. Finally, general up-to-date experience and benefits are reported. Application so far has mainly been focused on individuals and small groups.

Some early LM applications in technology are presented, and both methodology and results are discussed of:

1. The support of an extensive engineering project, to resolve fabrication problems in large steam turbines. Characteristics here are many closely cooperating people in a large number of nested manufacturing loops.

2. The support of a process improvement project for large turbogenerators, involving the varnishing of stator sheets. It is demonstrated that both engineering and human factors need to be considered to identify and correct root causes of problems [20].

Conclusions concern the salient role of communication, language, and the human factors in many fields and activities. LM features, capabilities, and benefits are summarized [21]. Last but not the least, future applications and potential extensions of the method are outlined.

\section{COMMUNICATION AND HUMAN FACTORS}

\subsection{Communication}

Life is primarily characterized by communication; other features are motion, continuous change, diversity, adaptation, etc. In general, communication is permanently happening within each living system as well as between several such systems. Both internal and external exchange of information involves an emitter and a receiver; in between is a transmitting medium. Additionally acoustic, chemical, optic codes are needed to transmit a message. Examples for external communications are the dance of honeybees [13], the whistling language of dolphins, or the chemical language of superorganisms, like ants [8]. Also the world of odors in orchids and flowers belongs to external communication. Human languages and interpersonal communication emerged during the cultural evolution [13, 19]. Our intrapersonal communication system is equally complex and distributed all over our body. The brain part works mainly unconsciously, and it largely determines our judgment, thinking, feeling, decisions, and actions (Chapter 4).

Switching from biology to technology: control engineering and cybernetics are designing much simpler communication systems. Figure 1 shows the simplest building block for a controlled transmission of an input signal $\mathrm{X}$ through a control system towards an output $\mathrm{Y}$ : a closed control loop with negative feedback.

This simple circuit is very general and applicable in many fields. Suitable circuit design with negative feedback assures a desirable, inherently stable behavior. Generally in nature and biocybernetics we find very large, complex, nested and interlinked control loops: open and closed controls 


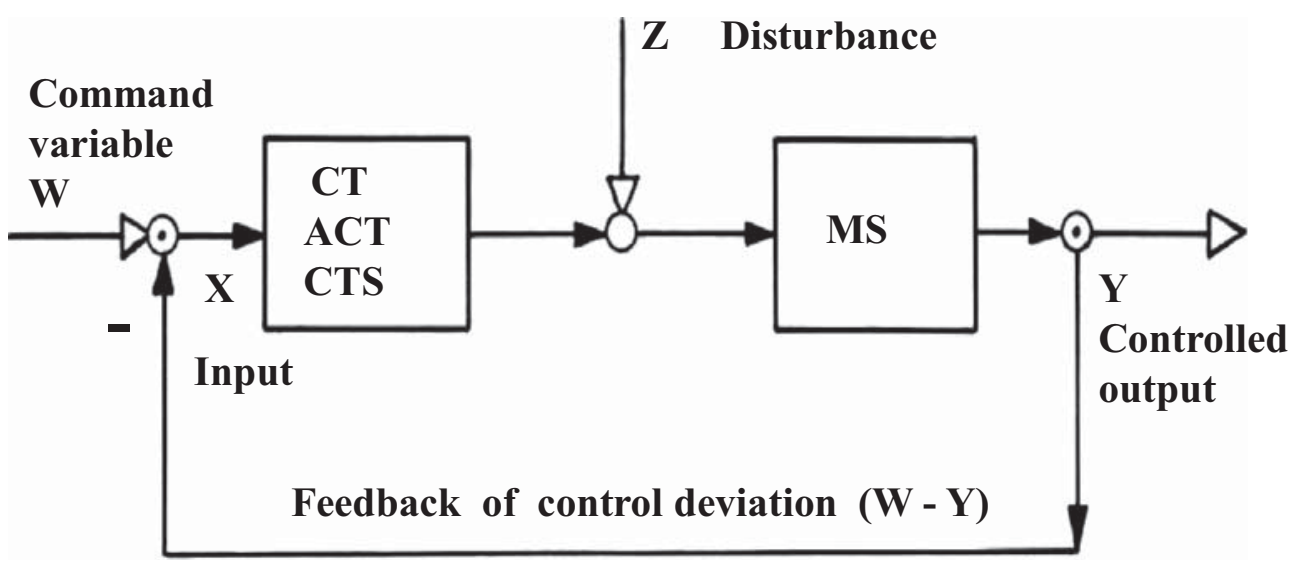

CT Controller ACT Actuator CTS Control system MS Measuring system

Figure 1: Closed control loop: Feedback of control deviation ( $\mathbf{W}-\mathbf{Y})$ filters out the disturbance $\mathbf{Z}$.

with multiple and connected command variables $\mathrm{W}$, disturbances $\mathrm{Z}$, properly chosen damping, redundancies, etc. They are designed for stability, i.e. for a dominating negative feedback. Natural systems are robust, i.e. they are insensitive toward disturbances $\mathrm{Z}$.

They cope with time delays and allow transients far off the equilibrium into a new, stable configuration. Quite often there is a 'fuzzy-logic' incorporated to maintain recognition of general patterns. In complex situations the fuzzy perspective is superior to purely deterministic procedures. It should also be kept in mind that natural systems usually behave differently than simpler control circuits in engineering.

Figure 2 is an analogue to the closed control loop in Fig. 1. It represents a closed loop basic element for many human activities, for instance in technology: engineering product and process improvements (PPI), root cause and damage analyses, general design processes and simulations. The schematic is equally applicable to self-management or any other human activity for systematic work toward a given target or improvement. The important five steps cover:

- FOCUS: Define objectives, targets compared to a chosen best 'benchmark'. Describe the problems. Quantify the 'gap' and the success. Define and fix the indicators to measure the success.

- ANALYZE: Observe and measure all relevant parts of the CURRENT system. Determine the deviation $\Delta$ against the chosen best benchmark. Correlate the data, recognize patterns. Weigh the importance of the findings, i.e. the biggest contributors to the 'gap' or problems. Concentrate and downselect.

- IMPROVE: Develop ideas, changes, corrections, which will eliminate or reduce the problems. Determine their cause-effect relation. Weigh those corrections toward their biggest effects. Downselect.

- CHECK: Add the downselected corrections temporarily to the system. Measure the new 'gap' between CURRENT and NEW. If the target is reached, continue with IMPLEMENT. If the target is not reached, return to ANALYZE to consider more and new findings.

- IMPLEMENT: Add the downselected corrections permanently to the system. Document all findings and corrections. Train people and secure results for the future. 


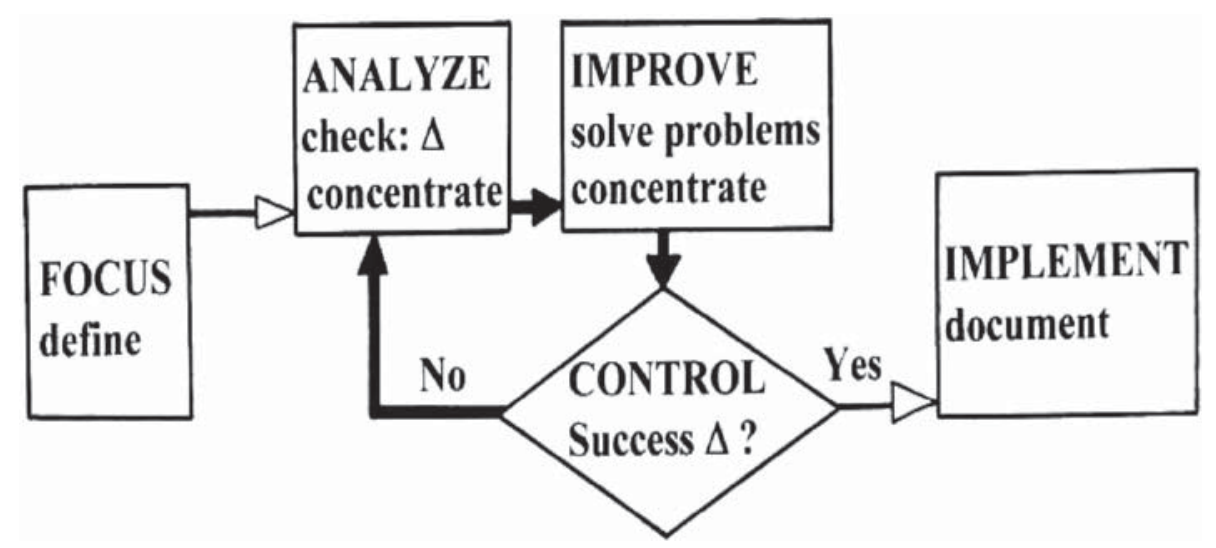

Figure 2: Basic closed loop schematic for systematic, self-controlled improvement processes.

Experience shows that in practice - say in engineering project management - this loop is quite often not closed and the key phase ANALYZE is rushed through too fast. Both failures prevent real, viable success [5, 7]. Generally speaking, additional failures are observed: a lack of knowledge of systems as well as circuitries themselves, a dominating positive feedback (instability), insufficient damping, lack of robustness, and improper time delays. Those failures may lead to steep transients and overshoots, violent instabilities or collapses with uncontrolled consequential damages [21].

\subsection{Human factors}

Research on the human factor originated from aviation, where a large number of critical decisions are concentrated on one person, the pilot, who is operating a complex technical system. Nowadays the term human factor stands for much more general psychic, cognitive, and social influence factors in both socio-technical as well as man-machine systems. It has many facets, therefore we prefer here the plural "human factors" (HF) according to [3]. The HF is manifesting in interpersonal communication - both with negative (human errors) and positive (initiative, stimulation, motivation, creativity, etc.) aspects (Chapter 5). The part "human error" (HE) plays an important role in technology, production, and operation of complex technical apparatus. Extending the definitions (I) to (III) of Makabe [5-7], one can distinguish four groups of HE (percent of occurrence in technology, 2006) [6]:

(I) INADVERTENT

Lack of attention. Random, not predictable (ca. 30\%)

(II) TECHNIQUE Lack of skill /knowledge. Consistent, witting (ca. 20\%)

(III) WILLFUL

Deliberate /with good intent (ca. 5\%)

Deliberate /sabotage or terrorism

(IV) AMBIGUOUS LANGUAGE

Lack of clarity/precision. Misleading wording. Consistent, predictable (ca. 45\%)

Two-thirds of HE are often predictable within (II) and (IV); most of them can be prevented. Prevention of (I) may be possible by fool-proof design, built-in interlocks, fail-safing, and by checklists [7]. 
The other much more sophisticated part of HF is present everywhere: between two individuals, in groups, and in large organizations. It plays an increasing role in today's society, because technical capabilities advance fast, whereas non-technical human skills basically remain the same. So the gap is rising, the bottleneck HF surfaces. The question is how to assess, manage, and optimize this HF to improve our quality of life and work.

\section{COMPARISON WITH NATURE}

\subsection{Learning from nature}

We ourselves are part of nature, and it is best for humanity to cooperate with it. Acting against nature leads to self-destruction. Saving our resources and maintaining the environment favors the future of mankind. Working with nature means to understand and learn from its principles. Examples and proof are given in [6-8]. Nature maximizes flexibility and adaptability. Generally the consumption of material, energy, and information is minimized, and on a broader scale almost zero waste is remaining.

Principles for design and material development in nature represent a huge field for innovation in human technology $[17,18]$. In spite of the complex human brain with its HF, a comparison with nature is useful, since it unveils parallels and analogues, which help to understand ourselves. Also general applications are visible, concerning:

- Communication and information

- Control and organization

- Creativity, optimization, and improvement

Of particular interest is to look how nature handles the dynamic complexity of large, stable, and self-regulating networks: we find many examples for efficient transport, processing, control, and storage of large amounts of data. Undisturbed transmission, clear /unbiased perception, and evaluation of signals or patterns can be found. There are masterpieces of logistics in superorganisms like ants or honeybees [12, 13]: planning, division of work, delegation of activities, etc. Large states are organized in flat hierarchies, which are loosely interlinked. We can also learn from nature fault-tolerance and how to organize viable, self-regulating processes. The design of robust, inherently stable systems is typical for nature as well.

All these natural features have been optimized throughout evolution. They have been proven over 600 million years, continuously being adapted to the current environment. This resource represents a rich pool of ideas and solutions for many human fields. Bionics already combines biology and technology for many benefits.

\subsection{Biological and mechanical examples}

A recently discovered biological example is given in Fig. 3, showing mutualism, an example for a self-controlled symbiosis between plants and animals [14-16]. It represents a controlled symbiosis between three partners, a tree and two animals in the east African savannahs: the Acacia trees Acacia drepanolobium - large mammals (giraffes, elephants, etc.) - special ants. The whole system is in equilibrium via a well balanced 'cost-benefit' relation between all three. The ants get free lodging and nectar food from the tree. In turn the ants protect the trees: they bite the mammals, when they try to eat too much of their leaves $[15,16]$. An interesting experiment has been 


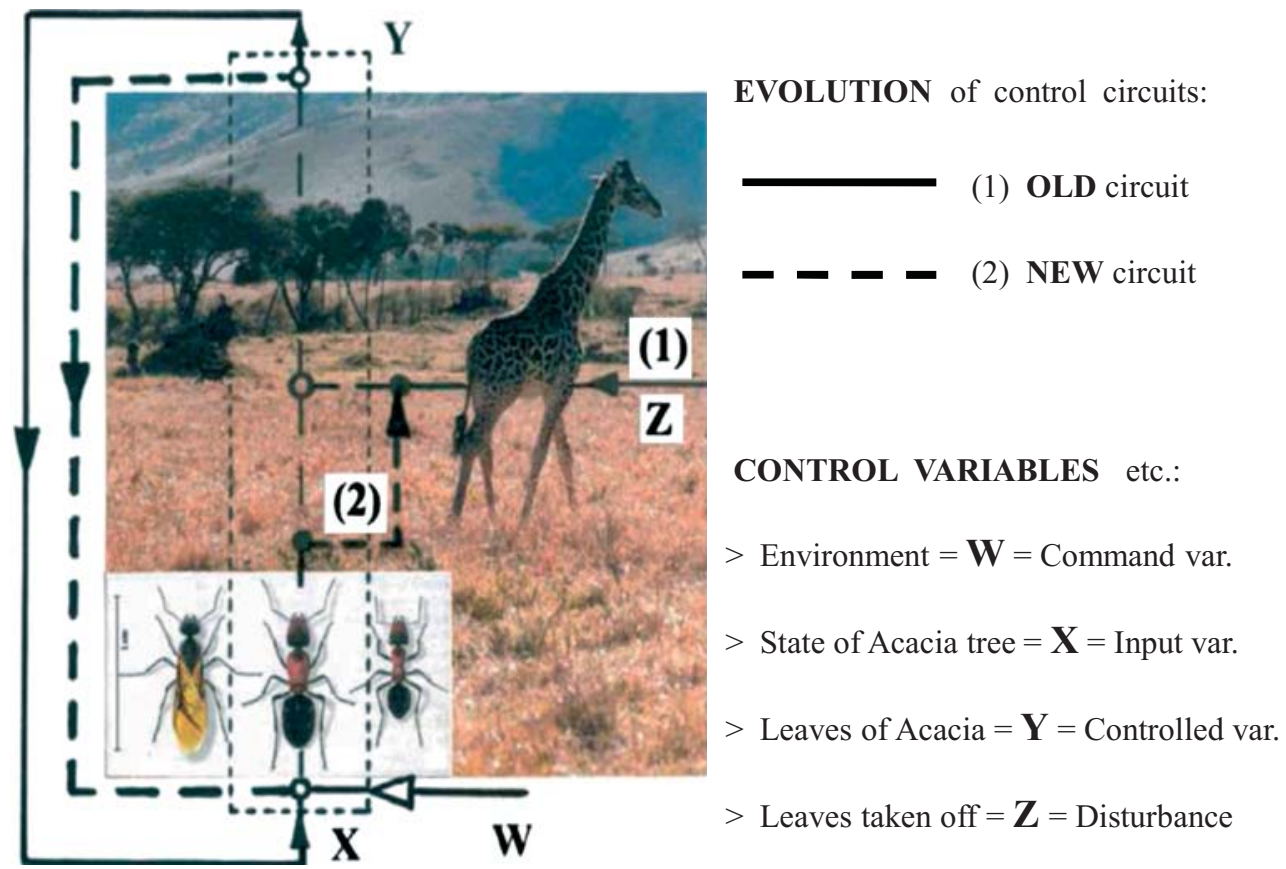

Figure 3: Mutualism, a stable, self-controlled symbiosis between Acacia trees, mammals, and ants in Africa.

performed in Kenya: researchers set up fences over 10 years around some Acacia trees, 'cutting off' the mammals. The basic control circuit indicated in Fig. 3 was interrupted. New systems emerged relatively fast, and the 'OLD' control circuit changed to new, intermediate but stable constellations. New circuits 'NEW' started to control the systems via the key variables W, X, Y, Z as indicated in Figs 1, 3.

The trees did not loose their leaves anymore, so they stopped to provide housing and nectar. Consequently the ants - especially Crematogaster mimosae suffered from the disrupted symbiosis. In a short circuit they hired scale insects as partners, which started to suck the Acacia juice. The ants in turn lived from their honeydew. Other inferior ants stepped in, protecting the trees against hostile ants by cropping off the leaves. The Acacia trees could not distinguish, so they restarted to provide housing and nectar again. But cheating is only a transition in evolution. After several intermediate strategies, long term, more balanced systems emerged.

Some mechanical examples are used, to demonstrate the behavior of systems far off their equilibria [8-10]. Figure 4 represents a transversely loaded, flat arch made from mild steel with a defined yield point. Gradually rising the central force $\mathrm{F}$ in a deformation-controlled manner 0 - 1 - 2 yields the typical characteristic $\mathrm{F}(\mathrm{y})$. Within $1-2$, the system is overloaded, but is still in equilibrium. If the force reaches a critical elastic peak value given by,

$$
\mathrm{F} \geq \mathrm{F}_{\text {crit }}=\operatorname{const}\left(\mathrm{E} \mathrm{I}_{\mathrm{y}}\right) / 1^{2}
$$

Geometric and material nonlinearities enter, a local plastic hinge may form in the center. Crossing the critical point 2 , the beam 'snaps through', quickly passing through an unstable, intermediate 
state 2 - 5. Point 5 is called indifferent, and beyond 5, stresses are redistributed. The whole process is a self-controlled, purely elastic or elastoplastic buckling. During the deformation-controlled loading, the force F(y) drops off and rises again (see $2-5$ - 3 in Fig. 4). Due to the irreversible elastic or elastoplastic deformation there is no way back to 5, and 'dissipative structures' [9-11] are freezing in the new shape, enabling for another configuration with the stable branch $5-3-4$. From the minimum 5 on the load, F rises again, exceeding the previous maximum at 3 . The principal force diagram $\mathrm{F}(\mathrm{y})$ demonstrates the first loading path (and subsequent reloadings) 0 - 1 - 2 - 5 - 3 - 4 with an unloading via the hysteresis $4-3-2-1-0$. Conservation of total energy and with the aid of an elastic potential $\mathrm{U}_{\mathrm{E}}$ (purely elastic deformation), three phases can be distinguished:

Stability: $0-1-2 \& 5-3-4$ with $\mathrm{U}_{\mathrm{E}}=$ Minimum \& $\delta \mathrm{U}_{\mathrm{E}}=0, \delta^{2} \mathrm{U}_{\mathrm{E}}>0$

Indifference: Points $2 \& 5$ with $\delta \mathrm{U}_{\mathrm{E}}=0, \delta^{2} \mathrm{U}_{\mathrm{E}}=0$

Instability: 2 - 5 with $\mathrm{U}_{\mathrm{E}}=$ Maximum $\& \delta \mathrm{U}_{\mathrm{E}}=0, \delta^{2} \mathrm{U}_{\mathrm{E}}<0$

A more complex application of a self-controlled 3D buckling process has been patented in 1993 [9]. Since then a wide field of applications have developed. Figure 5 gives an example of the 'Wölbstrukturierung', showing a thin-walled metal cylinder, which has been structured by a slight, external overpressure and a special line pattern for internal support. The regular, hexagonal 'dimples' are self-assembled by the structure itself: it attains a shape, which always satisfies the law of minimum total energy $\mathrm{E}_{\mathrm{T}}$ according to:

$$
\mathrm{E}_{\mathrm{T}}=\text { elastic }+ \text { plastic }=\mathrm{E}_{\mathrm{EL}}+\mathrm{E}_{\mathrm{PL}}=\text { Minimum }
$$

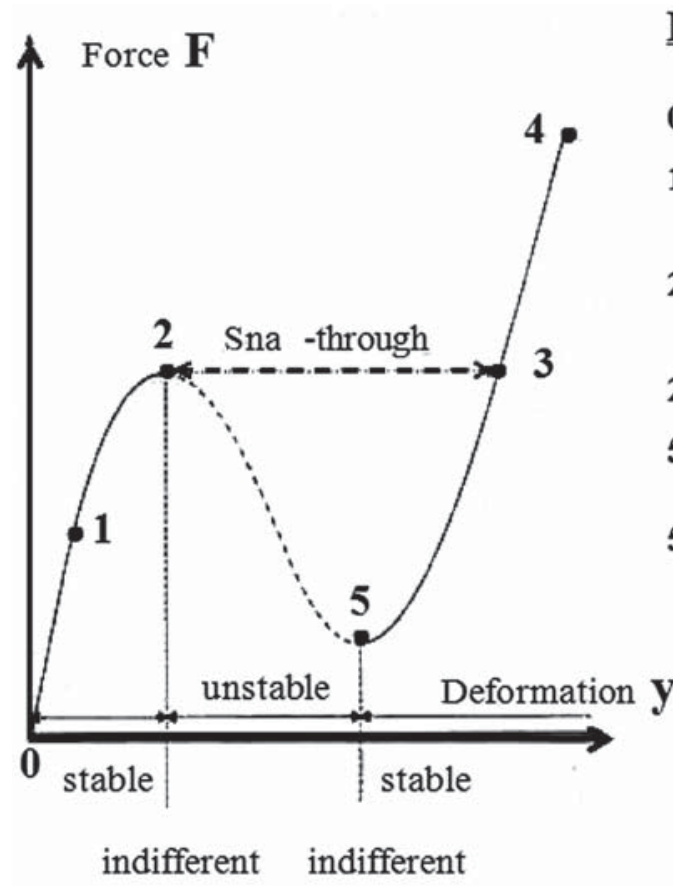

Flat arch with central loading:

0 - 1 Linear elastic range.

1 - 2 Large deformation/elastic elastoplastic deformation, stable

2 Critical rbifurcation point, indifferent

2 - 5 Unstable range

5 Minimum force, indifferent

5 - 3 - 4 Large deformation /elastic or elastoplastic deformation. stable

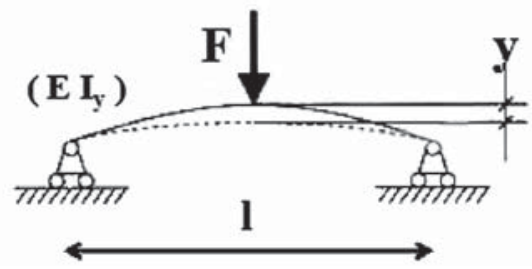

Figure 4: Stabilization (1): Self-controlled buckling of a flat arch (after F. Mirtsch, [9]). 


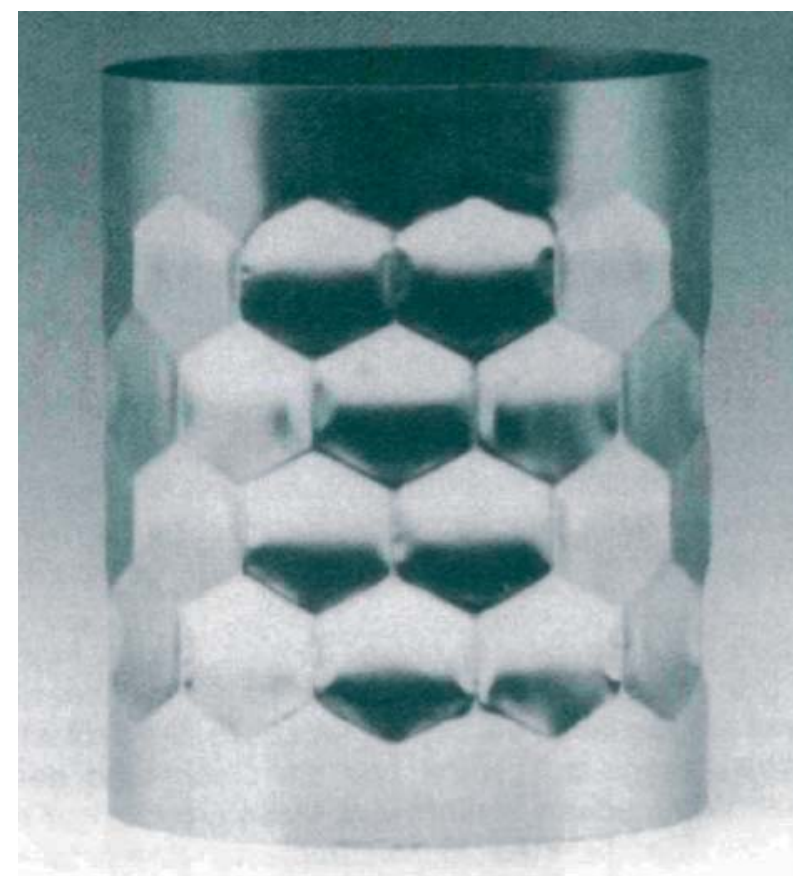

\section{FUNCTIONS:}

$>$ Save material \& weight

$>$ Stiffen a component

$>$ Reduce \& equalize stresses

$>$ Improve heat transfer

$>$ Save energy in fabrication

$>$ Supress noise \& vibrations

\section{APPLICATIONS:}

$>$ Automotive etc.

$>$ Light reflectors, interior design

$>$ Chemical \& process engineering

$>$ Heat exchangers \& cooling

$>$ Building technology

$>$ Packaging industry

Figure 5: Bionic structuring of a cylinder via self-controlled buckling. "Wölbstrukturierung" [9].

As in biology there are many examples in physics for systems with particular stabilizing mechanisms ('dissipative structures'), for instance:

Phenomenon

Stabilizing mechanism

BENARD-cells: self-controlled formation of hexagonal free-convection cells between a hot and a cold plate $(\Delta \mathrm{T})$.

Wavy or cell-structured cloud formations: similar effects as with BENARD-cells.

Activation of a laser beam: exceeding a critical stimulation rate causes the coherent emission of a laser beam.
A small flow disturbance leads to a new configuration with much higher heat flux performance across the plates ( $\Delta \mathrm{T}$ constant).

Layered $\Delta \mathrm{T}$ in conjunction with a small starting disturbance. Formation of regular cell structures. Positive feedback between stimulation and light radiation gives rise to steep power increase, switching from irregular light to a powerful laser.

\subsection{Inspirations for a new approach}

Many observations in nature show analogues in biology, physics, and chemistry, which partly form the basis for an integral approach to assess and optimize the human factors. Before describing a corresponding method, some highlights from nature are mentioned as general inspirations for humanity:

- Work with nature, not against it

- Involve all human senses. Use data reduction 
- Proceed from the 'periphery', not head-on

- Use fuzziness, don`t focus on details only

- Look at the whole system in an integral way

- Aim at a clear, unbiased communication

- Besides 'hard' factors, utilize 'soft' factors as well

\section{AN INTEGRAL APPROACH}

\subsection{Origination and features}

The focus of this paper is on an integral, new approach to improve the constitution of individuals and the quality of decision making. The corresponding Limbionik ${ }^{\circledR}$ Method (LM) emerged from observing human behavior and nature $[19,21]$. After comprehensive literature reviews and inspiring discussions between the authors, the LM has been developed and applied to individuals and groups since 2006. The word Limbionik ${ }^{\circledR}$ is registered in Europe, and it combines the three words 'limbo' (to be in limbo, well balanced) - 'biology' (get inspired from nature) - 'technique' (method).

Three items characterize the basic features of the LM as a method as well as a philosophy:

- Communication with information flow, cross-linked thinking, proper use of language. Identification of biased information, individual perception

- Personal control and organization with systematic methodology, self-management, and self-help

- Optimization, creativity, and improvement with stable, viable solutions

The main focus and objectives for practical applications are: for individuals to improve the quality of life toward success, satisfaction, and happiness. At the same time to optimize the physical, mental, and emotional constitution. For groups and teams to manage the HF, focus on team success and close the loops or gaps, respectively. For organizations to foster continuous improvement, broad motivation, and to strengthen decision-making as well as flexibility and speed. Alternative, smart business models may become visible as well.

\subsection{Philosophy and method}

The LM postulates an 'Urbewusstsein' (UB) for human individuals, Fig. 6. It characterizes the dynamic, complex interactions between three key instances: $\mathrm{P}_{\mathrm{G}}, \mathrm{P}_{\mathrm{K}}$, and $\mathrm{P}_{\mathrm{E}}$, which are continuously shaping the personal 'mental landscape' and 'script' of each individual. The UB gives orientation, protection, as well as stimulation. The three personalizing instances are preselecting, filtering, protecting but also intralinking, associating toward new challenges, actions, partnerships, targets, etc. During our whole life they are subjected to external flows of information $\mathbf{i}_{\mathbf{E}}$, and they exchange their information $\mathbf{i}_{\mathbf{I}}$ internally as well (intrapersonal communication). As indicated in Fig. 6, all three can be described by ( [19]):

- Genetic memory $\mathbf{P}_{\mathbf{G}}$ : this pool contains the heritage and information from previous generations. It is continuously modified during the individual's life and finally transferred to the next generation.

- Personalizing $\mathbf{P}_{\mathbf{K}}$ : this instance stores, controls, and weighs all information and knowledge, which is constantly obtained from society, media, and through other people's opinions.

- Personalizing $\mathbf{P}_{\mathbf{E}}$ : this instance stores, compares, and weighs all personal information, which comes from the surrounding world, the environment, and ecosystems.

Finally, the described multilevel interactions are continuously controlled and coordinated by the "Control center" (CC), Fig. 6. 


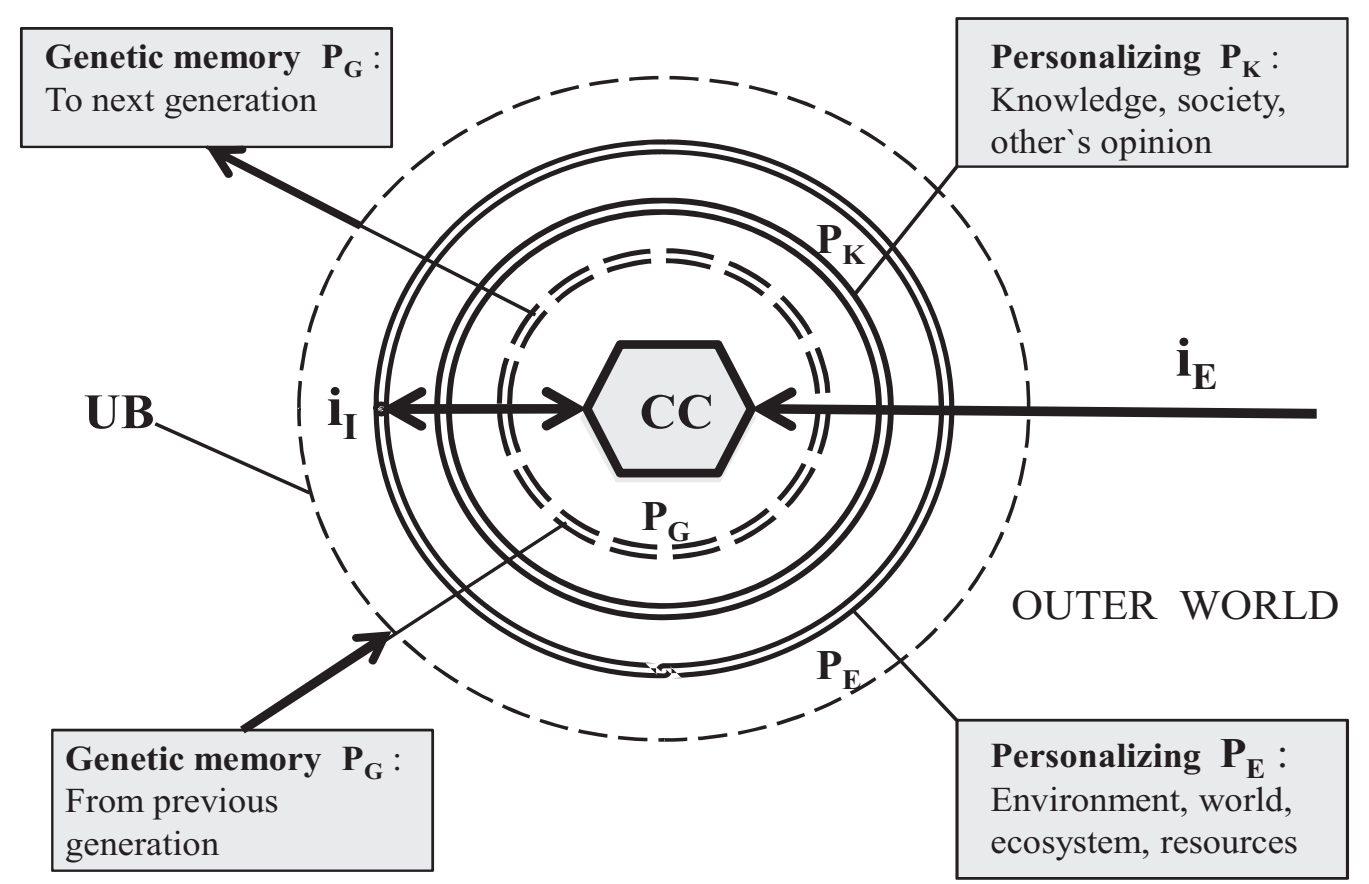

Figure 6: Human "Urbewusstsein" (UB): External $\mathbf{i}_{\mathbf{E}}$ and intrapersonal information $\mathbf{i}_{\mathbf{I}}$. Personalizing instances $\mathbf{P}_{\mathbf{G}}, \mathbf{P}_{\mathbf{K}}, \mathbf{P}_{\mathbf{E}^{*}}$. Control center $\mathbf{C C}$.

The interaction and communication between two persons is visualized in a simplified manner in Fig. 7, exchanging the mutual flows of information $\mathbf{i}_{\mathbf{E}, \mathbf{1 2}}$ and $\mathbf{i}_{\mathbf{E}, \mathbf{2 1}}$. Both personalizing groups of dynamic filters are very active, and they cross-influence each other. To a large degree this happens unconsciously.

It gets even more sophisticated, when considering language, wording, emotions, and bias with deliberate or unintentional distortion of information. Both persons with their UB1 and UB2 may be in positive or negative 'resonance'.

Figure 8 illustrates the interpersonal communication with additional facets, chances, and misunderstandings: nonverbal communication, body language, and group dynamics are coming into play as well.

If working with the LM for individuals or groups, the 'trainer' should be more adequately called a 'mover' or a 'temporary pilot', who makes the client to become aware of his own UB such that unconscious and hidden parts are unveiled. The clients or groups are self-teaching; they are always actively involved in recognizing their personalizing instances. They are widening and optimizing them toward new perspectives and solutions.

The 'mover' in turn applies a number of ways and means, which allow the client to 'dance freely with his UB' (in limbo, in balance). In a well balanced procedure some of these means include:

- Incorporating arts, music, emotions besides the rationale

- Approaching playfully from the client's periphery, not head-on

- Involving all human senses to achieve 'light moving' of the client

- Combining fuzziness, mirroring, and provocation ('shaking grate')

- Including puzzling with rationale as well 


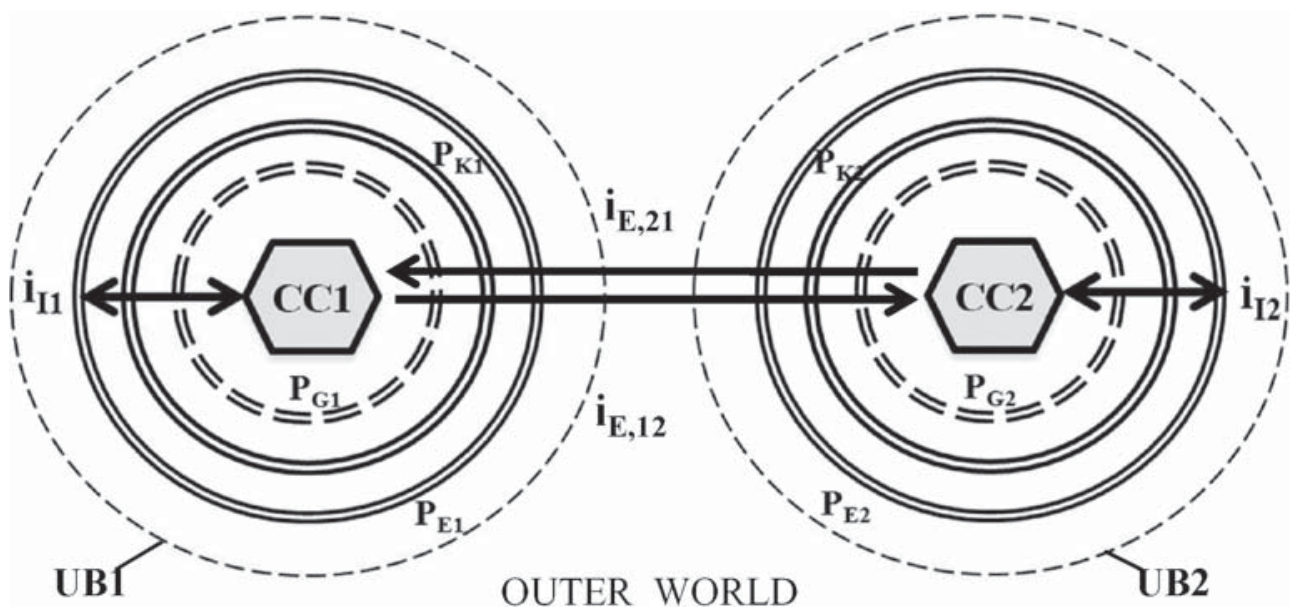

Figure 7: Interaction between humans: exchange of information $\mathbf{i}_{\mathbf{E}}$ (up to $10^{9} \mathrm{bits} / \mathrm{s}$ ). Personalizations within UB1 and UB2. Filtered cross-over with understanding and misunderstanding.

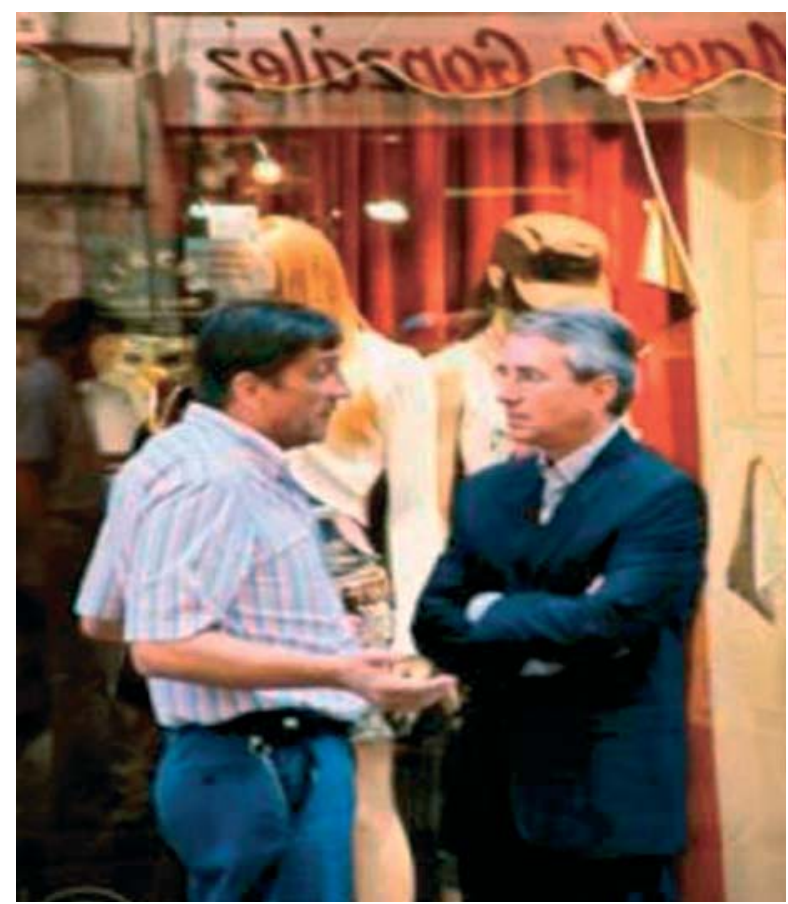

\section{INTERPERSONAL COMMUNICATION:}

$>$ Language

$>$ Choice of words

$>$ Precision /bias

$>$ Accentuation

$>$ Emotion

$>$ Verbal \& nonverbal

$>$ Body-language

$>$ Group dynamics

$>$ other......

Figure 8: Interpersonal communication: many facets and chances.

Finally eight assumptions are listed, underlying both the philosophy and the methodology of the LM:

- All creatures and life are characterized by communication, motion, continuous change, and diversity.

- Every human being represents an interlinked system of body, mind, and soul. Every individual owns a UB, which significantly affects his person. 
- The world is composed of complex systems, which are affecting each other, as well as each human being.

- Each individual is responsible for himself, for his actions and failures. Everybody is actively responsible for human society and for the world`s future.

- Diversity and prosperity are self-evident parts of life and nature.

- Nature is dynamic and highly efficient. In every situation the best is achieved with the least. In addition there is a tremendous potential for self-assembly and self-repair.

- Art is an opening process, allowing for unlimited thinking, fostering innovative and solutionoriented activity. It is also raising human perception.

- Technology is a continuously changing field, which constantly influences mankind. Humans are becoming less vulnerable for adversities and problems.

\subsection{Benefits and examples}

The LM makes people fit for our current accelerating pace of life. It gives support for self-help and self-management. The client identifies what is, contrasting it with his perception through the filters. Not only the perspectives are changing, but new routes become visible with more degrees of freedom. A self-motivation is triggered with broader views. In practice, clients often experience this transition as a 'switching process'. The benefits range from personal success, quality of life and happiness to clearly better decision-making within organizations. New, smart business strategies may lead to sustainable success.

In individuals, disturbances such as the well known boreout- and burnout- syndrome are very common. As a practical example, Fig. 9 shows several phases, which are typical for cases of a burnout. There is a striking similarity to the example described in Fig. 4, though the human processes, of course,

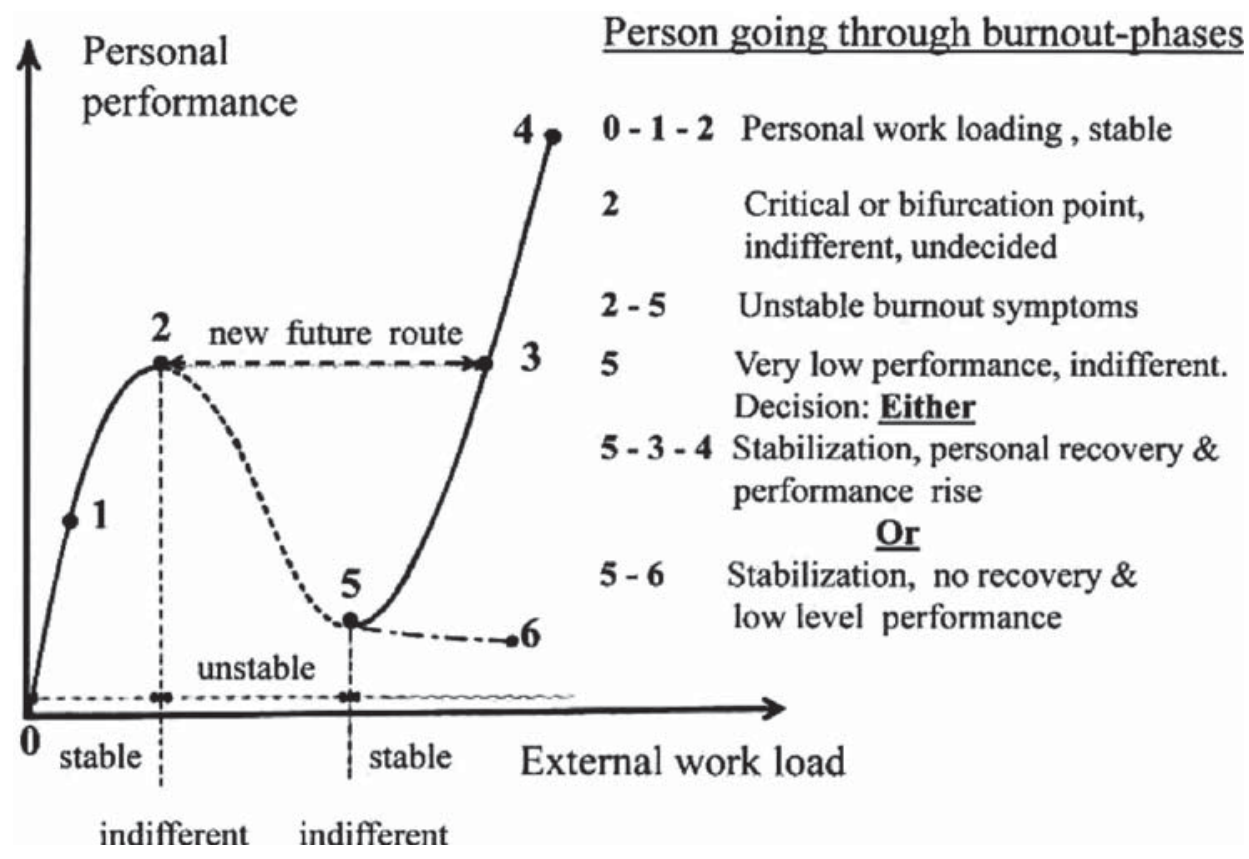

Figure 9: Stabilization (2): Person with burnout syndrome. Overloading, stabilization, and possible recovery. 
are much more complex than the self-controlled buckling of an arch. One very big difference in humans is their 'free will' at the decision point 5. To keep it simple, there are basically two routes to go:

3. Either stabilize with personal recovery and performance rise

4. Or stabilize without recovery and low-level performance

Once the successful route (1) has been chosen, the path never drops back to 5 . In case of decreasing work load (unloading in Fig. 4), the path follows 4 - 3 - 2 - 1. Analogues shown in Fig. 4 and Fig. 9 or other cross-comparisons within nature help to understand complex phenomena. When applying the LM, quite often the improved configuration is 'frozen in', it is irreversible. Several cases of successful recoveries and burnout prevention have been experienced [21].

\section{LM APPLICATION FOR ENGINEERING PROJECTS}

Technology, engineering, and fabrication offer a huge field to assess, manage, and optimize the HF. There is an ideal application for the LM. Very little publications do exist in this rather new, fast developing field; but there is a high potential [4,5]. Early applications of the basic LM tools have been performed in product- and process improvement projects (PPI) [7]. The surprising result from such projects revealed that the majority of the problem contributing root causes originate in the 'human' area $\left(\mathrm{RC}_{\mathrm{H}}\right)$; only a small part in the 'machine' or hardware area $\left(\mathrm{RC}_{\mathrm{M}}\right)$. The human area $\mathrm{H}$ is controlled by the HF, including different types of human errors (Chapter 2.2). Evaluating ca. 35 PPI-projects resulted in 70 to $90 \%$ root-causes originating from the human area:

$$
\left(\mathrm{RC}_{\mathrm{H}}\right) /\left(\mathrm{RC}_{\mathrm{H}}+\mathrm{RC}_{\mathrm{M}}\right)=0.70 \text { to } 0.90
$$

In production, all 'human' areas involve interfaces between man-man, man-machine, man-product, or man-measuring tool. This chapter describes recent LM supports for two extensive engineering/ fabrication projects: (i) Large low pressure steam turbines (ii) Turbogenerator stator cores. Experience and findings are typical; they can be transferred to other branches in engineering.

\subsection{Low pressure steam turbines}

Large steam turbosets are important machines in any power plant for electricity generation. The most challenging component being the low pressure section with its long, rotating, highly loaded last stage blades (LSB), shown in Fig. 10. The forged blades are currently up to circa $2 \mathrm{~m}$ long. Nevertheless, manufacturing tolerances especially in machining the blade fir-tree-root and rotor hub grooves are within circa $\pm 0.05 \mathrm{~mm}$. One of the reasons is the extremely high centrifugal force, which has to be transmitted to the rotor hub. This force level currently reaches up to 1000 tons per blade under operating speeds of 50 or 60 cps. Main LSB data are summarized in Fig. 10.

Steam turbine and LSB manufacturing of this category involves complex processes, many nested loops with a high number of man-man and man-machine interfaces. Due to the rising high level of technical know-how, the constant nontechnical human skills become a dominating bottleneck. In addition, nowadays a high percentage of both engineers and workers are from foreign countries, with different languages and mentalities.

Frequent problems in producing a sufficiently accurate and uniform radial gap $r_{R}$ lead to an extensive Six Sigma project (A). At that time the project was named 'Forged LSB tip-to-tip diameter after balancing'. Consequently, the findings concentrated on the blade manufacturing processes. As a result, many additional QA-steps were introduced into the blade fabrication.

However, there was no real success over years. Many costly NCs(nonconformances) and delays caused customer irritation. So a broader Six Sigma project (B) was triggered, with a different approach, covering the whole system. Small deviations from several specified manufacturing dimensions may 


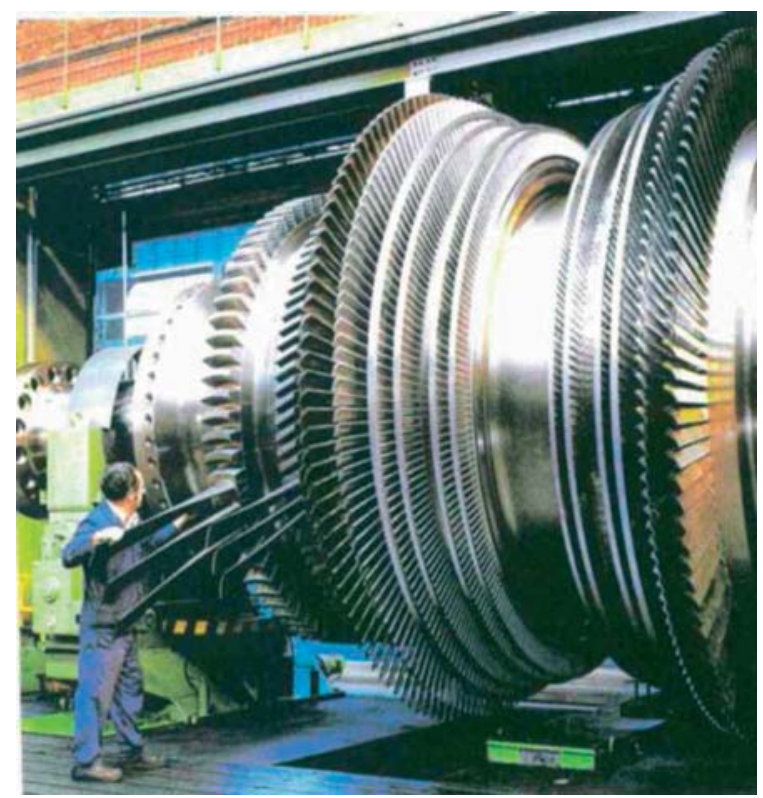

Low pressure

STEAM TURBINE (LPT):

Max. power $\mathbf{P}_{\text {LPT }}=300 . \mathrm{MW}$

LAST STAGE BLADE

(LSB) maximum data (2010):

$>$ Length $\mathbf{L}_{\mathbf{B}}=2.0 \mathrm{~m}$

$>$ Diameter $\mathbf{D}_{\mathbf{T}}=4.5 \mathrm{~m}$

(tip-to-tip)

$>$ Radial clearance $\Delta \mathbf{r}_{\mathbf{R}}=8 . \mathrm{mm}$

$>$ Blade tip speed $\mathbf{u}=600 . \mathrm{m} / \mathrm{s}$

$>$ Centrifugal force $\mathbf{F}_{\mathbf{C}}=1000 . \mathrm{t}$ (per blade)

$>$ Number of blades $\mathbf{z}_{\mathbf{B}}=75$

(per perimeter)

Figure 10: Large, double-flow, low pressure steam turbine (LPT) with typical last stage blade (LSB) data.

cause varying and large deviations in the tip-to-tip diameters $\mathrm{D}_{\mathrm{i}}$ of all $\mathrm{z}_{\mathrm{B}}$ blades per row, as indicated in Fig. 11. That was the time to apply the basic elements of the LM, and integrally analyze the whole LPT-system: engineering, production, quality assurance of rotors, blades, and stators. Three types of NC-origins were expected (with $\mathbf{H}=$ human-related, $\mathbf{M}=$ machine, hardware-related):

- H Production, engineering, etc.: the broad HF phenomena with biased information, misunderstanding, diverging interests, arrogance, prestige, vanity, envy, etc.

- H Production, engineering, etc.: human errors from lack of training, language/understanding, and attention.

- M Production: pure technical, hardware, CNC-machines, etc.

The self-controlling improvement loop (Fig. 2) was followed systematically. First - in contrast to the earlier project (A) - the integral project (B) was renamed 'Gaps between blade tips and stator contour after final rotor-stator assembly', reflecting the new philosophy. The complete system was mapped, analyzed, and measured covering blades, rotors, and stators - including assembly and balancing. All engineers, managers, foremen, and workers got involved this time. The earlier project (A) had been largely driven from two polarizing attitudes:

- Rotor fabrication: 'Our rotors are perfect. No changes required. The problem is in the blades'.

- Blades fabrication: 'We want to produce the best blades. All our steps will be analyzed for potential improvements'. 


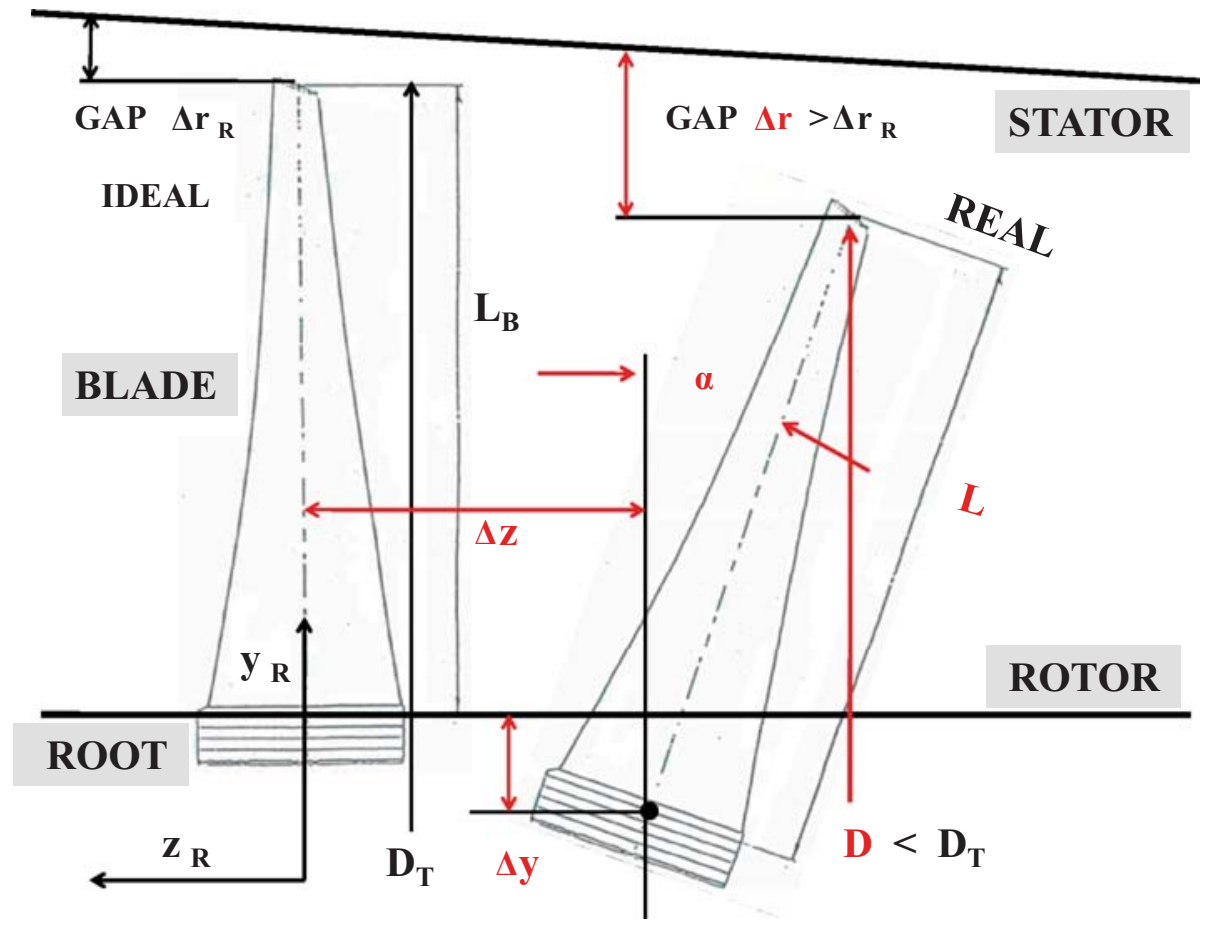

Figure 11: One row of last stage blades in an LPT: ideal and real position. The deviations $\Delta \mathbf{y}, \Delta \mathbf{z}, \alpha$, and real $\mathbf{L}$ systematically increase 'local' gaps $\Delta \mathbf{r}$ and decrease diameters $\mathbf{D}$ (specified values: $\Delta \mathbf{r}_{\mathbf{R}}, \mathbf{L}_{\mathbf{B}}$, and $\mathbf{D}_{\mathbf{T}}$ ).

Analyses for the project (B) were started with open, extensive interviews, cross-checks, and sanity checks on all management and working levels, to extract everybody`s experience. Also, all involved bilingual documents, manuals, and instructions were examined for clear, precise wording, free from misunderstanding. It was very important during that phase to generate confidence, openness, and respect toward each other. Mistakes and errors are nothing evil, they just present NCs, which are vital for continuous improvement and learning. Nobody should hide or ignore this potential. The general fear factor - the frustration of the workers and foremen, when talking to some ignorant engineers in the past - everybody's tendency to hide mistakes etc. - had to be overcome. It was equally important to differentiate facts from opinions and to identify individual perception and filters. A broad measuring program was set up on several LPTs with statistical and trend analyses (Six Sigma). Additional investigations covered: error progression, tolerance consistency, sensitivity checks, FMEA(failure mode effect analysis), and EMEA(error mode effect analysis). Twelve independent root-cause groups were identified, with a high 'human' content $\mathrm{RC}_{\mathrm{H}}(83 \%)$ :

$$
\mathrm{RC}_{\mathrm{H}} /\left(\mathrm{RC}_{\mathrm{H}}+\mathrm{RC}_{\mathrm{M}}\right)=0.83
$$




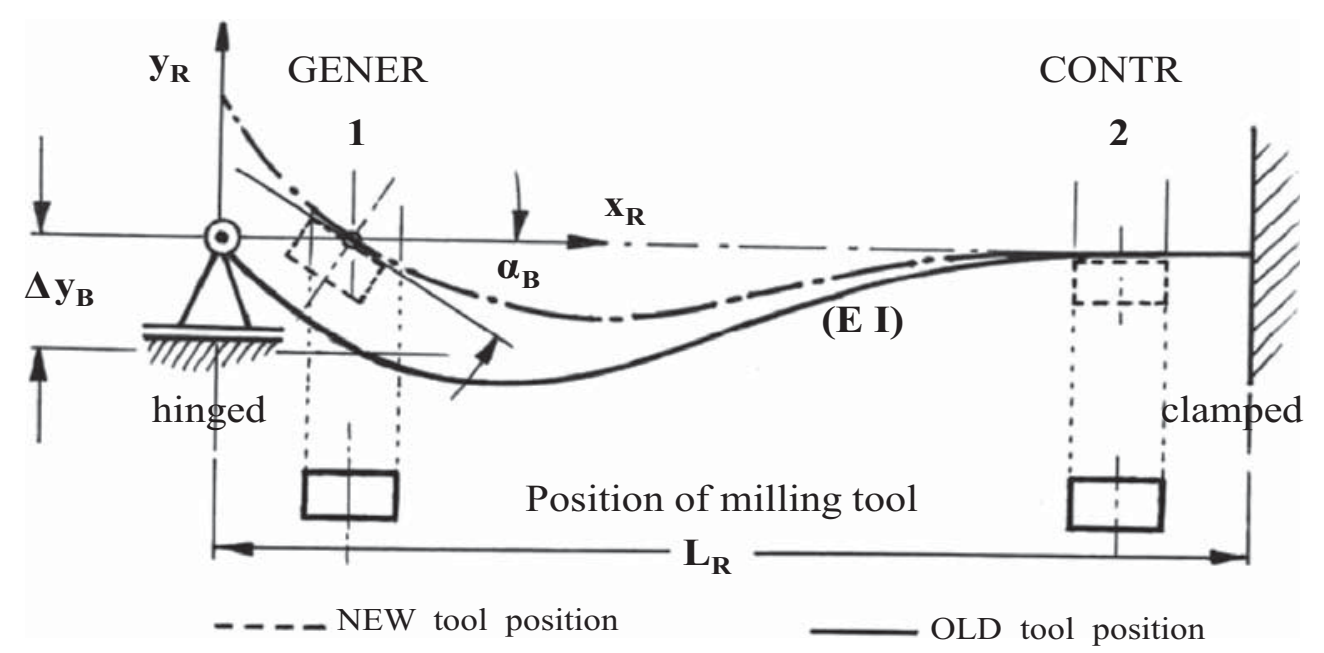

Figure 12: Clamping of rotor to mill blade grooves at $\mathbf{1}$ and $\mathbf{2}$ : Neglecting $\Delta \mathbf{y}_{\mathbf{B}}, \alpha_{\mathbf{B}}$ produces wrong grooves at $\mathbf{1}$.

Often RCs and corrections are surprisingly simple or inexpensive: see Fig. 12, 'Correction for rotor bending line'. Five most important contributors (current RCs) with corrective actions were finally downselected:

Current RCs:

Incomplete, wrong engineering specs (only $\mathrm{D}_{\max }$ specified and tolerated)

Milling of blade grooves in rotor (neglecting bending line of rotor forging during milling)

Assembly and securing of blades in rotor (Unclear communication and operation manuals)

Neglecting balancing effects (settling, etc.)

Many foreign languages (misunderstandings)

\section{Corrective actions:}

Specify and tolerate $\mathrm{D}_{\text {max }}, \mathrm{D}_{\text {mean }}$, and $\mathrm{C}_{\mathrm{PK}}$ (for the $\mathrm{D}_{\mathrm{i}}$ in each stage)

Correct position of milling tool for bending line

Clear quantifications for assembly and securing

Measure settling, etc. prior and after balancing.

Final correction after balancing via grinding off $\mathrm{D}_{\mathrm{i}}$ Introduce multilingual, clear instructions

\subsection{Turbogenerator stator core}

High mechanical stresses, vibrations, cooling of leads, and aging of insulation make large turbogenerators one of the most challenging rotating apparatus for electricity generation. Figure 13 indicates the stator core lamination to minimize eddy current losses in the iron. Circa 10000 thin sheets are manually stacked for the core iron after thoroughly varnishing, i.e. insulating both sides. Coating thickness $\mathrm{s}_{\mathrm{M}}$ needs to be extremely uniform across each sheet and from sheet-to-sheet. This is to prevent hot spots with possible disastrous iron fires during operation. The varnish thickness $\mathrm{s}_{\mathrm{M}}$ should on the other hand be as thin as possible for a high iron content in the core. 


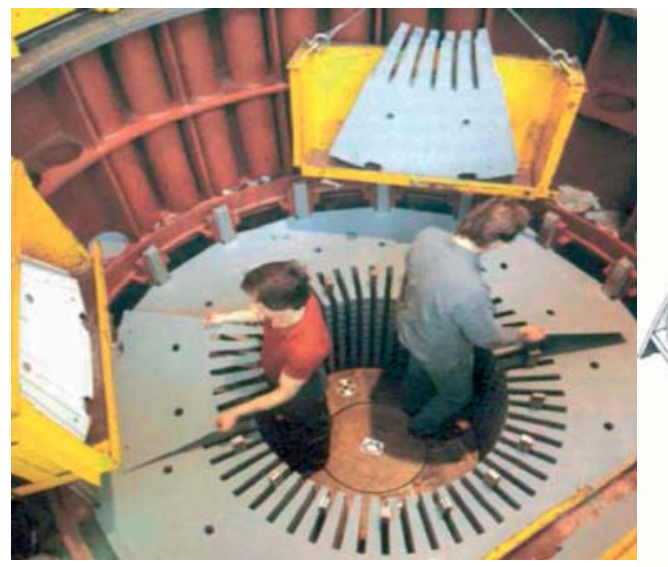

Stacking of sheet segments to stator core after varnishing both sides

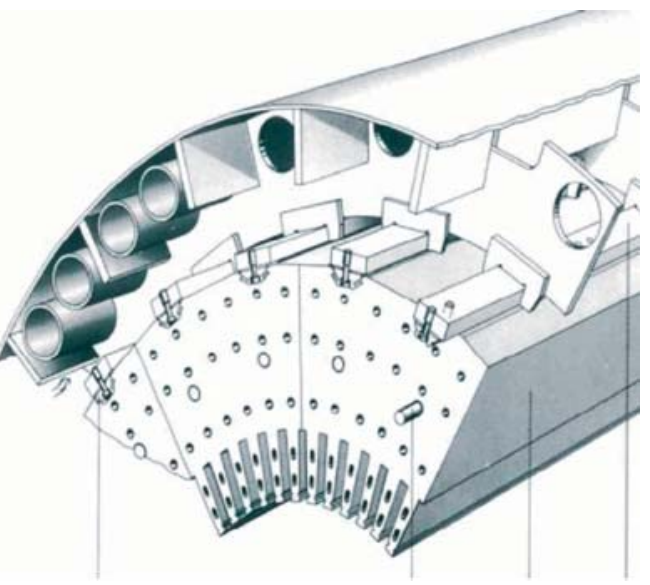

Design of stator core body from thin, insulated sheets reducing losses

Figure 13: Turbogenerator stator core: stacking of thin sheets after thoroughly varnishing both sides.

Previous varnish processes with random sampling showed too high scatter of the $\mathrm{s}_{\mathrm{M}}$, waviness across each sheet, high scrap rates, and costly overall NCs (Fig. 14). An integral Six Sigma project was set up incorporating LM principles to identify shortcomings in engineering specs (prescribed s, UCL(upper control limit), LCL(lower control limit), and $\mathrm{T}_{\mathrm{S}}$ ), statistical procedures and sampling, measurement techniques for $\mathrm{s}_{\mathrm{M}}$, and process capability $\mathrm{C}_{\mathrm{PK}}$. In addition, both engineering and human factors were incorporated in all investigations. Main objectives for the process improvement project were to:

- Find explanations for the high scatter of the varnish thickness $s_{\mathrm{M}}$. Identify and eliminate root causes of problems.

- Introduce good and constant quality by a robust, forgiving varnishing process.

- Reduce sheet scrap rate and NC-cost level. Varnish with zero defect.

- Avoid delays and field problems including iron fires.

Process capability $\mathrm{C}_{\mathrm{PK}}$ was successfully used to quantify varnishing, maching-, measurement-, or any other process step. For instance, for the mean varnish thickness $s_{M}$ per sheet, see Fig. 14 (sheetto-sheet $\mathrm{C}_{\mathrm{PK}, \mathrm{M}}$ ):

$$
\mathrm{C}_{\mathrm{PK}}=\mathrm{C}_{\mathrm{PK}, \mathrm{M}}=\left(\mathrm{T}_{\mathrm{S}}-2 \mathrm{E}_{\mathrm{M}}\right) / 6 \sigma_{\mathrm{M}} \text { with an excentricity } \mathrm{E}_{\mathrm{M}}=\left|\mathrm{s}-\mathrm{s}_{\mathrm{M}}\right|
$$

in respect to a specified tolerance window $\mathrm{T}_{\mathrm{S}}=(\mathrm{UCL}-\mathrm{LCL})$.

Old processes were 'poor' with $\mathrm{C}_{\mathrm{PK}}$ circa 0.6. After eliminating main root causes, all new processes were centered toward 'very good' and robust with $\mathrm{C}_{\mathrm{PK}}$ circa 1.50 as indicated in Fig. 14. The varnishing process was effectively centered (reduction of $\mathrm{E}_{\mathrm{M}}$ ) and zero defect was reached by introducing statistical process control (SPC). For that the varnish temperature $\mathrm{T}_{\mathrm{V}}$, i.e. its viscosity was measured and continuously adjusted, so that the resulting varnish thickness $\mathrm{s}_{\mathrm{M}}$ was actively kept within the band UCL to LCL. SPC represented an automatic closed control circuit with $\mathrm{T}_{\mathrm{V}}$ as the command variable. 


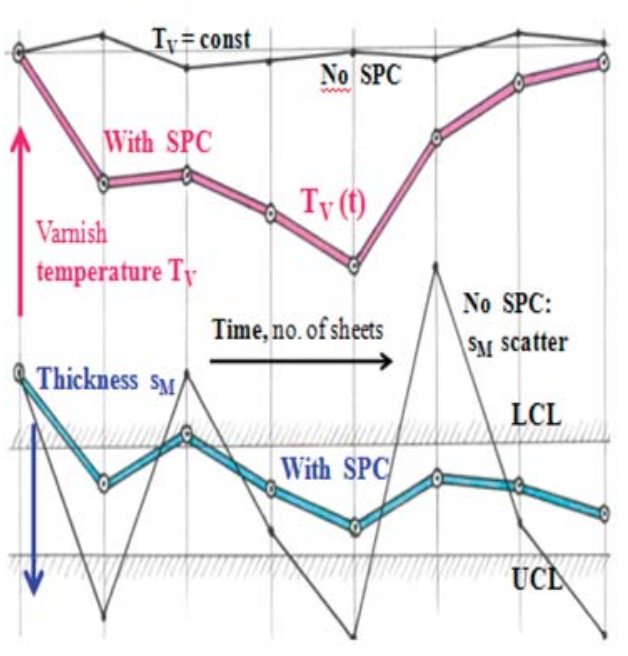

Zero-defect sheet varnishing via selfcontrol of thickness $\mathbf{s}_{\mathbf{M}}$ by command variable "Varnish temperature $\mathbf{T}_{\mathbf{V}}$ "

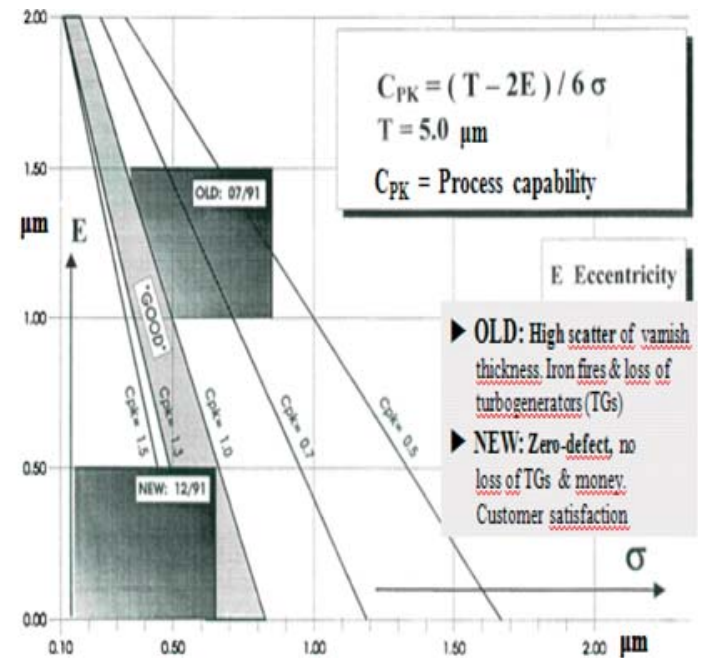

Centering of varnishing process from $\mathbf{C}_{\mathrm{PK}}=$ $\mathbf{0 . 6}$ (very poor) to $\mathbf{1 . 5}$ (very good) by introducing statistical process control (SPC)

Figure 14: Varnishing process with and without statistical process control (SPC): centering of process for zero defect.

The LM-assisted approach finally yielded a number of additional improvements during the project (group dynamics, motivation, etc.), as well as permanently afterward upstream and downstream the processes. Actions were introduced, based on:

- Quality of communication: enhancement and fostering regular, clear, unbiased communication between engineering and production.

- Personal control and organizational structures: installation of regular, multilingual cross-info between shift people. Introduction of check lists at key process steps. Change in-series process steps into parallel, loosely connected ones.

- Individual creativity with improvement and optimization. Self-motivation: installation of regular, closed-loop feedback teams in the shop for continuous improvement.

- Installation of 'robust processes' in both engineering and human areas.

\section{SUMMARY AND OUTLOOK}

Description has been given of a general assessment and optimization of the HF with broad applications in several fields of human activities, such as personal life, technology, economy, etc. Until now first experience was gained with an HF-based systematic method in individuals, groups, and in engineering organizations.

Our current situation is characterized by global, dense interrelations, accelerating growth and frequent worldwide crises. There is a strong need for alternative routes in many fields of human activities. In this context, the key role of communication is highlighted, which involves the human factors (HF). As part of this, the types of human errors are discussed. The much more complex HF itself is manifesting broadly with both positive and negative aspects in interpersonal communication. 
In spite of human complexity it is useful to observe nature and compare it with ourselves for a better understanding. First, a simple building block is described from control engineering and biocybernetics: a control circuit with negative feedback for stability and elimination of disturbances. Two examples are then presented from biology/zoology and mechanics:

- The mutualism, a self-regulated symbiosis between the Acacia tree, special ants, and large mammals in Africa. Fast adaptation and the emergence of new control circuits are demonstrated from an experiment in Kenya.

- The elastoplastic, self-controlled buckling of structures with unstable 'snap-through' demonstrates how new configurations are attained via stabilizing 'dissipative structures'. Similarly, the self-assembly of hexagonal dimples in sheet metal is utilized in technology since 1993 ("Wölbstrukturierung").

The examples illustrate self-regulation, adaptation, and stability in living systems. They also show some basic principles in nature (minimum of total energy, etc.)

In the main part, an integral approach based on the above findings is presented in detail: the Limbionik ${ }^{\circledR}$ Method (LM). The method and its underlying philosophy focus on interpersonal communication and the HF. It makes individuals and organizations fit for the accelerating pace of today's life. Origin, objectives, features, and assumptions of the methodology are discussed and practical applications are given. The 'Urbewusstsein' (UB) as the core model within the LM is described; it uses three personalizing instances to protect, stimulate, and guide the individual. Utilization of the UB helps to get access, to assess, and to optimize the HF.

Until now experience has been gained with individuals and groups or teams. Several examples illustrate the application with benefits and findings in two different areas:

1. The successful treatment of several clients, who went through phases typical for a burnout syndrome: the stabilizing mechanism here is the client's own realization of his UB-filters. Self-motivation and self-management make him decide the recovery path at the 'bifurcation' point 2.

2. The successful PPI project support in steam turbine and turbogenerator engineering /fabrication applying the LM principles: inclusion of the HF into the engineering Six Sigma procedure unveiled mainly human deficiencies (ca. $80 \%$ of root causes originate in the human area). Main results in these particular projects:

- Drastic reduction of problems and quality related costs

- Successful introduction of robust processes, both in machine and human areas

- Installation of self-motivation. Introduction of permanent improvement processes

- Customer satisfaction, enhanced competitiveness, and future orientation

Basic characteristics of the LM philosophy are summarized as:

- Integral, system-oriented approach

- Involvement of all human senses

- Consideration of both 'hard' and 'soft' factors

- Combination of mirroring, provocation, fuzziness, and puzzling with rationale

Future work will cover the following activities on both HF and LM:

- Extend the research on the role and assessment of human errors and the HF.

- Gain more experience for problem solution with the integral approach including the HF. 
- Apply the LM in other fields of human activities toward qualitative improvement and economic success.

- Develop and test quantitative indicators to assess success- and quality-factors within the LM (similar to $\mathrm{C}_{\mathrm{PK}}$ ).

\begin{tabular}{|c|c|c|}
\hline & & NOMENCLATURE \\
\hline $\mathrm{C}_{\mathrm{pk}}$ & - & process capability index \\
\hline $\mathrm{D}_{\mathrm{T}}^{\mathrm{ph}}$ & $\mathrm{m}$ & specified diameter at blade tip-to-tip \\
\hline $\mathrm{D}\left(\mathrm{D}_{\mathrm{i}}\right)$ & $\mathrm{m}$ & real diameter at tip-to-tip (at blade i) \\
\hline E & $\mathrm{N} / \mathrm{m}^{2}$ & Young's modulus \\
\hline $\mathrm{E}_{\mathrm{M}}$ & $\mathrm{m}$ & process excentricity for $s_{M}$ \\
\hline $\mathrm{E}_{\mathrm{T}}$ & $\mathrm{J}$ & total mechanical energy \\
\hline $\mathrm{E}_{\mathrm{EL}}$ & $\mathrm{J}$ & elastic mechanical energy \\
\hline $\mathrm{E}_{\mathrm{PL}}^{\mathrm{LL}}$ & $\mathrm{J}$ & plastic mechanical energy \\
\hline$\left(E I_{v}\right)$ & $\mathrm{Nm}^{2}$ & bending stiffness \\
\hline $\mathrm{F}\left(\mathrm{F}_{\mathrm{C}}\right)$ & $\mathrm{N}$ & force (centrifugal force) \\
\hline $\mathrm{i}$ & bit & information \\
\hline 1 & $\mathrm{~m}$ & beam length \\
\hline $\mathrm{L}$ & $\mathrm{m}$ & real blade length \\
\hline $\mathrm{L}_{\mathrm{B}}$ & $\mathrm{m}$ & specified blade length \\
\hline $\mathrm{L}_{\mathrm{R}}$ & $\mathrm{m}$ & rotor length \\
\hline $\mathrm{m}$ & $\mathrm{kg}$ & mass \\
\hline M & $\mathrm{Nm}$ & bending moment \\
\hline $\mathrm{P}$ & MW & power \\
\hline $\mathrm{P}_{\mathrm{G}} \mathrm{P}_{\mathrm{K}} \mathrm{P}_{\mathrm{E}}$ & - & personalizing instances, Fig. 6 \\
\hline $\mathrm{RC}_{\mathrm{H}}$ & - & number of root causes originating from human area \\
\hline $\mathrm{RC}_{\mathrm{M}}$ & - & number of root causes originating from machine area \\
\hline$\Delta \mathrm{r}$ & $\mathrm{m}$ & real radial clearance, Fig. 13 \\
\hline$\Delta r_{R}$ & $\mathrm{~m}$ & specified radial clearance, Fig. 13 \\
\hline s & $\mathrm{m}$ & specified mean varnish thickness across one sheet \\
\hline $\mathrm{s}_{\mathrm{M}}$ & $\mathrm{m}$ & mean real varnish thickness across one sheet \\
\hline$\Delta \mathrm{T}$ & ${ }^{\circ} \mathrm{K}$ & differential temperature \\
\hline $\mathrm{T}_{\mathrm{S}}$ & $\mathrm{m}$ & specified tolerance band for the mean varnish thickness $\mathrm{s}_{\mathrm{M}}$ \\
\hline $\mathrm{u}$ & $\mathrm{m} / \mathrm{s}$ & peripheral velocity at blade tip \\
\hline $\mathrm{U}_{\mathrm{E}}$ & $\mathrm{J}$ & elastic potential \\
\hline $\mathrm{W}^{\mathrm{c}}$ & - & command variable \\
\hline $\mathrm{X}$ & - & input variable \\
\hline $\mathrm{Y}$ & - & variable to be controlled (output) \\
\hline $\mathrm{y}$ & $\mathrm{m}$ & displacement \\
\hline$\Delta \mathrm{y}$ & $\mathrm{m}$ & real radial position of blade, Fig. 11 \\
\hline$\Delta \mathrm{y}_{\mathrm{B}}$ & $\mathrm{m}$ & displacement at bending line, Fig. 12 \\
\hline $\mathrm{z}_{\mathrm{B}}$ & - & number of blades per row \\
\hline $\mathrm{Z}$ & - & disturbance \\
\hline$\alpha$ & $\mathrm{rad}$ & inclination of real blade, Fig. 11 \\
\hline$\alpha_{\mathrm{B}}$ & $\mathrm{rad}$ & slope at bending line, Fig. 12 \\
\hline$\sigma_{M}^{D}$ & $\mathrm{~m}$ & standard deviation for $\mathrm{s}_{\mathrm{M}}$ \\
\hline
\end{tabular}




\section{REFERENCES}

[1] ZEIT Online, Wirtschaftsbionik, 4/2010.

[2] Vester, F., Die Kunst, vernetzt zu denken, dtv, 2007.

[3] Badke-Schaub, P., Human Factors, Book, Springer Verlag, Berlin, 2008. doi:http://dx.doi. org/10.1007/978-3-540-72321-9

[4] Stanton, J., The analysis, correction and prevention of human errors. Presentation, Florida USA, $11 / 2004$.

[5] Watson, G.H., Benchmarking: A discovery...six sigma learning, Human Error Analysis, Dr. Makabe, $1 / 2009$.

[6] R. Liebe, L. Liebe, Learning From Nature, WIT, 4/2008 and TAE, Esslingen, etc. since 10/2006.

[7] www.turbo-improve-consult.de

[8] Liebe, R., Design and nature, Lecture notes, University of Stuttgart, since 2006.

[9] Mirtsch, F., Bionisches Material durch Wölbstrukturieren, BIONA-Report 15, 2000.

[10] Prigogine, I., Dissipative structures, dynamics and entropy, From PhD dissertation, Italy, 1975.

[11] Jetschke, G., Mathematik der Selbstorganisation, VEB Deutscher Verlag, Harry Deutsch GmbH, Frankfurt a.M. Germany, 1985.

[12] Junker, R., et al., Evolution, ein kritisches Lehrbuch, 6. Auflage, Weyel Verlag, Giessen, Germany, 2006.

[13] Tautz, J., Phänomen Honigbiene, Spektrum Elsevier, Elsevier GmbH, Spektrum Akad. Verlag, Heidelberg, Germany, 2007.

[14] GEO kompakt 11, Insekten, 2007.

[15] Neue Züricher Zeitung, 16.1.2008.

[16] T.M. Palmer “Breakdown of an ant-plant mutualism”, Science, 319, pp. 192-195, 2008.

[17] Fuller, R.B., Your Private Sky - The Art of Design Science, ed. J. Krausse et al., Verlag Lars Müller: Zürich, "Fuller Research", pp.276-313, 1999. doi:http://dx.doi.org/10.1126/ science. 1151579

[18] Bejan, A. \& Lorente, S., The constructal law of design and evolution in nature. Philosophical Transactions of the Royal Society B, Biological Sciences, 365, pp. 1335-1347, 2010. doi:http://dx.doi.org/10.1098/rstb.2009.0302

[19] www.peropti.de

[20] Malik, F., Management, Campus, 2007.

[21] Liebe, R., Liebe, L., Limbionik ${ }^{\circledR}$ Merkmale und Anwendungen. Lernen von der Natur für Technik, Fertigung, Organisation. Zukunftssicherung im Turbomaschinenbau. Limbionik ${ }^{\circledR}$ für Individuen und Organisationen. Courses, Workshops, Seminars in Germany, since 10/2006. 